\title{
Effect of a Self-Instruction Package on Cognitive Performance among Egyptian and Saudi Pediatric Nursing Students
}

\author{
Azza Abdel Moghny Attia and Eman Abdel Fattah Hassan \\ Pediatric Nursing Department, Faculty of Nursing, Cairo University, Egypt
}

\begin{abstract}
Nursing educators should recognize the need to develop innovative teaching strategies that would enhance student learning. Aim: The study aimed to evaluate the effect of applying a self-instruction package on cognitive performance among pediatric nursing students in Egyptian and Saudi settings. Methods: This quasiexperimental study was carried out at the Faculty of Nursing, Cairo-University, Egypt and the College of Nursing, Hail University, Kingdom of Saudi Arabia (KSA) on a sample of convenience of 100 Egyptian and 90 Saudi nursing students. A self-instruction unit addressing lower respiratory infections, especially pneumonia was prepared and applied. The effectiveness was measured through pre-post-testing. Results: The results showed that the students in both samples had high levels of success in the posttests reaching in total $99.0 \%$ in the Egyptian sample and $100.0 \%$ in the Saudi sample. The lowest level of success in both samples were in the "compare" level of knowledge, $91.0 \%$ and $94.4 \%$ in the Egyptian and Saudi samples, respectively. As for the rates by question type, it reached 100.0\% for "MCQ" and "list" types in both samples. Saudi students had significantly higher scores in the "know" level of knowledge ( $p=0.04)$, and in the "list" ( $p=0.02)$ and "compare/match" ( $p=0.004)$ types of questions, but with no statistically significant difference in total score $(p=0.20)$. In multivariate analysis, the module was the main statistically significant independent positive predictor of the knowledge score improvement at all levels of knowledge. The Egyptian nationality was a positive predictor for the "know" and "analyze" levels. Meanwhile, the female gender was a positive predictor of the "apply" level of knowledge. Additionally, the Egyptian nationality was a positive predictor for the "MCQ" and "list" types. Conclusion: the self-instruction package is effective in improving the cognitive performance of nursing students in Egypt and Saudi Arabia in all cognitive levels and used various types of questions. The study recommends the use of the package in nursing schools, and development of similar ones in different topics.
\end{abstract}

Keywords: active learning, faculty members, nursing students, pediatric nursing, self-instructional package, teaching strategies.

\section{Introduction}

The main objective in teaching pediatric content is to provide nursing students with the knowledge and skills to safely and competently care for children ${ }^{[1]}$. Learning does not necessarily occur in formal educational settings because learners can learn all by themselves in informal settings ${ }^{[2]}$. Innovative teaching strategies can engage students in an active learning process. If they use these strategies well, nursing students are more likely to memorize the information associated with the lesson. Hence, it is important for nurse educators to select appropriate teaching strategies in order to deliver high-quality education ${ }^{[3]}$.

Active learning shifts the focus from the teacher and delivery of course content to the student and active engagement with the material. Through active learning techniques and modeling by the teacher, students abandon the traditional role of passive receptors, and learn and practice how to catch knowledge and skills and use them meaningfully. Research and anecdotal evidence overwhelmingly support the claim that students learn best when they engage with course material and actively participate in their learning. Yet, in the traditional teaching model teachers just pour concepts and information into students as receptacles ${ }^{[4]}$. Meanwhile, active learning requires appropriate learning environments with implementation of correct strategies ${ }^{[5]}$.

Taking a great deal of initiative in their own learning, learners can choose learning strategies independently of their teachers. To have a developed self, it is highly recommended that learners manage their own learning process through engagement in self-directed learning ${ }^{[2]}$. The degree of instructor's guidance to student while being "active" may vary according to the task and its place in a teaching unit. In an active learning environment, learners are immersed in experiences within which they engage in meaning-making inquiry, action, imagination, invention, interaction, hypothesizing and personal reflection ${ }^{[6]}$.

Self-instruction pertains to learning materials and conditions arranged so that students can proceed to learn on their own with little or no supervision ${ }^{[7]}$. A self-instruction module is one of the educational materials that help individualized learning. In self-instruction strategies, the student takes charge of the learning activity, while the teacher merely guides. In this cognitive learning strategy, the learning task is broken into steps. The learner directs and appraises himself/ herself as he/she goes through these steps. It also gives the learner an 
opportunity for self-evaluation, self-determination, and self-motivation ${ }^{[8]}$. However, it is important to go through the module in schematic way ${ }^{[9]}$. Nursing educators should recognize the need to develop innovative teaching strategies that would enhance student learning. Further research is needed to determine the best approach for teaching pediatric content ${ }^{[1]}$. Therefore, this study intends to ascertain whether, self-instruction strategy as a method of teaching can enhance the cognitive performance of pediatric students in two different settings.

\subsection{Aim of the study:}

The study aim was to evaluate the effect of applying a self-instruction package on cognitive performance among pediatric students in Egyptian and Saudi settings.

\subsection{The research hypothesis:}

The research hypothesis was that pediatric nursing students will score higher in their posttest after exposure to the self- instruction package regardless their nationality.

\subsection{Research design and setting:}

\section{Subjects and Methods}

A quasi-experimental design with pre-post assessment was used in this study, which was carried out at the Faculty of Nursing, Cairo-University, Egypt and the College of Nursing, Hail University, Kingdom of Saudi Arabia (KSA). The yearly registered students are approximately 250 students in the Egyptian setting and 60 to 120 in the Saudi setting. The two settings are using the credit-hour system.

\subsection{Subjects:}

A sample of convenience of pediatric nursing students who were eligible to be included in the study sample upon fulfilling the inclusion criteria of being full-time students in one of the two aforementioned study settings, at the third level, registered in pediatric nursing theory course, and having passed the courses of fundamentals of nursing, medical-surgical nursing or adult 2, and co-courses. Only repeater students were excluded from the study sample. The sample size was calculated to demonstrate an improvement in students' success rate by $50 \%$ or higher at $95 \%$ level of confidence and $80 \%$ power using the OpenEpi software program. Students were consecutively recruited according to the eligibility criteria. The final study sample included 100 Egyptian and 90 Saudi students. All Saudi students were females, while the Egyptian sample consisted of 48 males and 52 females. The mean ( \pm standard deviation) age of Egyptian students was $20.5 \pm 1.55$ while the mean age of Saudi students was $21.5 \pm 1.7$ years.

\subsection{Study intervention (self-instruction unit):}

The main researcher developed a self-instruction unit addressing lower respiratory infections, especially pneumonia. This topic was selected from the pediatric nursing theoretical content because pneumonia is the single largest infectious cause of death in children worldwide, accounting for $16 \%$ of all deaths of children under five years old. Moreover, pneumonia can be prevented with simple interventions, and treated with lowcost, low-tech medication and care ${ }^{[10]}$. Furthermore, the main researcher attended training in how to construct a self-instruction unit in the Center of Education Development, at the Faculty of Nursing, Cairo-University. The unit applied in this study was prepared by the researcher as a course requirement, and it was ranked first by education specialists.

The developed self-instruction unit covered all aspects of pneumonia including definition, risk factors predisposing to more severe and acute respiratory problems in young children, comparison between viral and bacterial pneumonia, clinical manifestations, investigations, and management. Different cognitive levels of knowledge were included such as know and recall, comprehend and compare, apply, analyze, and evaluate.

In the unit introduction, the student was asked to read the objectives carefully since they should be fulfilled at the end of the instructional package. To achieve the scientific content of the package, the student should carry out several instructional activities such as reading from the references at the end of the package at the library, using the digital library if online search is needed, and using the multipurpose lab to watch related educational videos. The student has the freedom to choose from these alternatives as is suitable for his/her readiness and abilities. The student was also instructed to check his/her knowledge through a self-assessment test. If the student gets $80 \%$ or more in this test, this may indicate that he/she has achieved the package objectives, and is ready for the posttest; otherwise, he/she had to restudy the package again.

A pre/posttest form was developed by the researchers in order to assess the levels of knowledge before and after the application of the self-instruction unit. It was designed according to the Intended Learning Outcomes (ILOs) mentioned in the course syllabus and based on pertinent literature review ${ }^{[11]}$. The test consisted of various types of questions built according to the type of Bloom's Taxonomy objectives ${ }^{[12]}$ so that the assessment techniques are most appropriate for measuring these objectives. The use of this taxonomy helps 
educators to build objectives that enhance students' abilities to apply acquired knowledge to practice ${ }^{[13]}$. Therefore, the types of questions set covered the simple and complex ILOs that should attained at all cognitive levels. The test included ten "MCQs," five "True/False," three "list/fill in the spaces," and two "compare/differentiate" questions. At the end of the form, the student was asked to write down his/her age, and gender.

\subsection{Study Maneuver:}

After securing necessary official permissions, the researchers in the two study settings met with the eligible students and introduced them to the self-instruction unit. They were advised to read the instructions of using the package carefully before undergoing the pretest. They were then administered the pretest. Students were offered three weeks to study the contents. The course tutor was available two days/week (Sunday and Tuesday) for two hours (12:00 to $14: 00 \mathrm{pm})$ to facilitate the self-learning process. To motivate the students, the post-test was allotted a score of ten from the total score of the pediatric course through arrangement with the head of the department. Whenever a student was ready to carry out the post-test, based on self-assessment and within the due date, the test was done.

\subsection{Administrative and ethical considerations:}

A formal approval to conduct the study was obtained from the heads of departments and the vice-deans for undergraduate affairs of the two Faculties of Nursing under study. The study protocol was approved by the research and ethics committees. The researchers introduced themselves to students, then the purpose of the study was explained and their written consent to participate was obtained. Additionally, students were assured that all gathered information will be confidential and will be used only for the purpose of the study. Als students were informed that they have the right to withdraw from the study at any time and the scores alloted for selfinstructional package was alloted for another assignment.

\subsection{Statistical analysis:}

Data entry and statistical analysis were done using SPSS 20 statistical software package. Quantitative data were compared the non-parametric Mann-Whitney test. Qualitative categorical variables were compared using chi-square test. Spearman rank correlation was used for assessment of the inter-relationships among quantitative variables and ranked ones. In order to identify the independent predictors of students' knowledge scores, multiple linear regression analysis was used, with analysis of variance for the full regression models. Statistical significance was considered at $\mathrm{p}$-value $<0.05$.

\section{Results}

Table 1 demonstrates generally low success rates in both samples before application of the intervention, 25.0\% and 7.8\% in total for the Egyptian and Saudi students, respectively. For Egyptian students, the lowest rates by knowledge level were in the "compare" and "evaluate" ones. The Saudi sample had similar low rates in these levels in addition to the level of "analyze." By question type, the two samples had the highest rates of success in "True/False" type and the lowest in the "compare/match" type.

After the implementation of the intervention, the same table shows that the students in both samples showed high levels of success reaching in total $99.0 \%$ in the Egyptian sample and $100.0 \%$ in the Saudi sample. The lowest level of success in both samples were in the "compare" level of knowledge, $91.0 \%$ and $94.4 \%$ in the Egyptian and Saudi samples, respectively. As for the rates by question type, it reached 100.0\% for "MCQ" and "list" types in both samples. Table 2 demonstrates that, before the intervention, the Egyptian students had statistically significantly higher scores in the knowledge levels of "know" and "analyze" $(\mathrm{p}<0.001)$. They also had higher scores in the MCQ $(\mathrm{p}=0.001)$ and "list" $(\mathrm{p}<0.001)$ types of questions. Their total mean score (52.6) was higher compared with their Saudi peers (43.3), $\mathrm{p}<0.001$.

After the implementation of the intervention, the table indicates very high total mean scores reaching 94.6\% in the Egyptian sample and $96.8 \%$ in the Saudi sample, with no statistically significant difference $(p=0.20)$. Meanwhile, Saudi students had significantly higher scores in the "know" level of knowledge $(p=0.04)$, and in the "list" $(p=0.02)$ and "compare/match" $(p=0.004)$ types of questions. As illustrated in Table 3, there were statistically significant weak to strong positive correlations among the students' score at various levels of knowledge of the Intended Learning Outcomes (ILOs). The weakest correlation was between the levels of "know" and "apply" ( $\mathrm{r}=0.307)$, whereas the strongest correlation was between the levels of "analyze" and "evaluate" ( $\mathrm{r}=0.828)$.

In Multivariate analysis, Table 4 indicates that the implementation of the module was the main statistically significant independent positive predictor of the knowledge score improvement at all levels of knowledge (ILOs). Additionally, the Egyptian nationality was a positive predictor for the "know" and "analyze" levels. Meanwhile, the female gender was a positive predictor of the "apply" level of knowledge. 
Concerning the multivariate analysis by types of questions, Table 5 again shows that the implementation of the module was the main statistically significant independent positive predictor of the knowledge score improvement in all types of questions. Additionally, the Egyptian nationality was a positive predictor for the "MCQ" and "list" types.

\section{Discussion}

The study results demonstrate that the self-instruction unit led to significant improvements in the knowledge scores of nursing students in the study settings in Egypt and Saudi Arabia. This lead to acceptance of the set research hypothesis. The finding is in congruence with the results of a study carried out in Saudi Arabia, which demonstrated that self-learning was better than traditional learning for nursing students in Albaha University ${ }^{[14]}$. Moreover, Rassin et al., ${ }^{[15]}$ showed that nurses preferred to take more responsibility of their own professional development through enhancing their self-learning skills. On the same line, Chiou et al., [16] highlighted that student-centered self-learning educational strategies are in accordance with the philosophy of nursing education and may foster the professional competence of nursing students.

The present study findings reveal higher success rates at the entry level among Egyptian students compared with the Saudi ones. However, in both settings. However, in both groups, the success rates were highest at the application and recall levels. The high recall level is expected since it is the easiest and lowest rank in the knowledge levels. Moreover, most of the pre-university education in both countries depends on this level. Meanwhile, the high rates in the application level could be attributed to the nature of the nursing sciences in general, and of the self-instruction unit in particular, where theory is mostly directly applied. At the other extreme, the success rates were lowest in the evaluation level of knowledge, which is quite expected given that it is the highest in rank. Nonetheless, all levels of knowledge are inter-related and the higher-rank levels are built on lower-rank ones. Thus, as the study results show, there were positive correlations among the scores at various knowledge levels. In agreement with this, the Faculty Center for Teaching and Learning ${ }^{[17]}$, stated that in the process of complex cognitive development, lower-level skills build into higher-order thinking.

Concerning the students' success rates according to the types of questions before the intervention, the current study revealed similar results in both settings. Thus, the highest rates of success were in the MCQ and True/False types of questions, whereas the lowest rates were in the "list" and "compare/match" types. This could be due to the fact that the MCQ and True/False types are associated with a high level of guessing, which would give a higher probability for correct answers only by chance. In agreement with this, Liu et al., ${ }^{[18]}$ in a study of the effect of question design on nursing students' assessment in China, concluded that the use of conventional MCQs should be reconsidered, as they only examine the recall of isolated knowledge facts. The 'All of the above' option should be avoided because it would increase the number of correct answers arrived at by guessing.

Nonetheless, the application of the present study intervention, i.e. the self-instruction unit, conduced to significantly better rates of success in both settings at all levels of knowledge, and for all types of questions. The findings indicate the effectiveness of the unit in helping students achieve all the ILOs at various cognitive levels, in addition to their ability to solve questions in all forms regardless their types and the related roles of chance in getting the correct answer. Such results demonstrate the utility of the self-instruction unit in promoting students' applied knowledge, which is the cornerstone of nursing practice. In this respect, Robin ${ }^{[19]}$ stressed that the higher-order cognitive levels of Analyze, Evaluate, and Create should be aimed at by nursing educators while preparing courses. This is essential for students to be competent in their future nursing profession and to be able deal with the complexities of their work in real life situations.

According to the present study findings, the means of the post-intervention scores among Saudi students were generally higher compared with those of the Egyptian students. The differences reached statistical significance the "know" or recall level of knowledge, as well as in the "list" and "compare/match" types of questions. However, there was no statistically significant difference in the total score post-intervention scores. These presumably better results among the Saudi students could have more than one explanation. The first is that their scores at the entry or pretest level were significantly lower, so that any change would be more evident. The second is that most Saudi students, approximately a half of them, are bridging students, i.e. diploma students who complete their study in the Faculty of Nursing to have bachelor degree in nursing. These are already working in the Ministry of Health, and they are very keen to face challenges to enhance their career. This may increase their readiness to learn as shown in a study in Al-Jouf, Saudi Arabia, which demonstrated high level of self-directed learning readiness among undergraduate nursing students, which reflects a positive implication for their education ${ }^{[20]}$.

The foregoing present study findings are in agreement with those of Anthony et al., ${ }^{[8]}$ who showed significant improvements in the posttest mean scores of students exposed to a self-instruction educational strategy. The author concluded that the self-instruction strategy gives the learners opportunities for selfevaluation, self-determination, and self-motivation. On the same line, other studies in Canada ${ }^{[21]}$ and in Pakistan 
Said et al., ${ }^{[22]}$ demonstrated high interests for learning with a high level of readiness in self-learning among bachelor degree nursing students. Furthermore, a study in China revealed statistically significant improvements in nurses' scores of knowledge and interpretation of the electrocardiogram after using self-learning handbook material ${ }^{[23]}$

The effectiveness of the current study self-instruction unit in the present study was further confirmed through multivariate analysis. The intervention was identified as the main independent positive predictor of students' knowledge scores. This was demonstrated at all levels of knowledge and in all types of questions. Moreover, it explained a high percentage of the variations in the students' scores. This success could be attributed to two factors. The first is the self-instruction unit content and structure, as well as its ease of use and clear instructions. Moreover, the self-assessment part embedded in the unit could have enhanced students' learning. Thus, the unit had the main characteristics of an adult self-learning module as defined by Pappas ${ }^{\text {[24] }}$. These characteristics include the ability to enhance learner's maturity, self-confidence, autonomy, and decisionmaking. Moreover, the unit was generally more practical, multi-tasking, purposeful, self-directed, and receptive to change. Such characteristics have a positive impact on students' motivation and ability to learn. The second factor is students' readiness to embark on self-learning and their eagerness to learn.

Apart from the effect of the self-instruction module on nursing students' knowledge scores at various levels and in different types of questions, two more factors were identified as co-predictors of some of these scores. These were the Egyptian nationality, which had a positive influence on the "know" and "analyze" levels, and the "MCQ" and "list" types of questions, and the female gender, which had a positive impact on the "apply" level of knowledge. The effect of the nationality could be related to differences in the pre-university educational system, as well as the types of questions often used in testing. As for the effect of the gender, it could be attributed to that the majority of the total sample were females, and the higher commitment among them to learn.

\section{Conclusion and Recommendations}

The developed self-instruction package showed effectiveness in improving the cognitive performance of bachelor degree nursing students in Egypt and Saudi Arabia. This was revealed in all cognitive levels and used various types of questions. The study recommends the use of the self-instruction package in nursing schools, and development of similar ones in different topics. Faculty members need to be trained in the development of such instructional materials, and in motivating students to use them.

\section{References}

[1]. Haines N., Beard L., Day M.,Mengel M., and Moody C. (2017): Where are the Children? -pediatrics in an integrated format, Journal of Nursing; Available at: http://rn-journal.com/journal-of-nursing/where-are-the-children-pediatrics-in-an-integrated-format. Accessed5/1/2017.

[2]. Tabatabaei O. The Effect of Self-Directed Learning on Critical Thinking of Iranian EFL Learners. . Journal of Educational and Social Research; 2012, 2:55-64.

[3]. Xu J-H. Toolbox of teaching strategies in nurse education. Chin Nurs Res.; 2016, 3:54e57. http://dx.doi.org/ 10.1016/j.cnre.2016.06.002

[4]. Rudasill, S. (2011), Instruction at FSU, "A Guide to Teaching and Learning Practices" 7 th. ed., The Florida State University.

[5]. Grabinger and Dunlap R., Scott and Joanna C. (2015): "Rich environments for active learning: a definition". Retrieved 25 September 2015.

[6]. Cranton P. (2012): Planning instruction for adult learners, 3rd.ed.,Toronto, Canada: Wall \& Emerson, p. 1257.

[7]. Random House Dictionary, (2017): Self-instructional. (n.d.) Dictionary.com Unabridged. Retrieved Feb 18, 2017 from Dictionary.com website http://www.dictionary.com/browse/self-instructional.

[8]. Anthony A., Michael E., and Victoria O. Effect of Self-instruction Strategy on the Achievement in Algebra of Students With Learning Difficulty in Mathematics. US-China Education Review A; 2012, 12: 1006-1021 Earlier title: US-China Education Review, ISSN 1548-6613.

[9]. Essays U.K. (2015): Guidelines for the Use Of Self Instructional Module Psychology Essay? utm_expid=30962938._Nb6m1ixT_a GX1K3CVQ TDw.0\&utm_referrer=https\%3A\%2F\%2Fwww.google. com.eg\%2F. Retrieved from https:/www.ukessays.com/essays/ psychology /guidelines-for-the-use-of-self-instructional-module-psychologyessay.php?utm_expid=309629-38._Nb6m1ixT_ aGX1K3 CVQTDw. 0\&utm_referrer=https\%3A\%2F\%2Fwww. google.com. eg\% $2 \mathrm{~F}$ ?cref $=1$

[10]. WHO, (2016): Pneumonia Fact sheet Updated September 2016. Available at http://www.who.int/mediacentre/factsheets/fs331/en/ Accessed at 24/11/2016.

[11]. Hockenberry, M. and Wilson, D. (2015): Wong's Nursing Care of Infants and Children, 10th. ed., Elsevier eBook , Mosby.

[12]. Bloom B.S. (1956): Taxonomy of Educational Objectives. Cognitive Domain. New York: McKay, Vol. 1:

[13]. Whei Ming S.M.A., and Osisek P.J. The Revised Bloom's Taxonomy: Implications for Educating Nurses. The Journal of Continuing Education in Nursing; 2011, 42 (Issue 7): 321-327.

[14]. Ahmed W., Alostaz Z., and Sammouri G. Effect of Self-Directed Learning on Knowledge Acquisition of Undergraduate Nursing Students in Albaha. AIMS Medical Science; 2016, Volume 3(Issue 3):237-247. DOI: 10.3934/medsci.2016.3.237

[15]. Rassin M., Kurzweil Y., and Maoz Y. Identification of the Learning Styles and "On-the-Job" Learning Methods Implemented by Nurses for Promoting Their Professional Knowledge and Skills. Int J Nurs Educ Scholarsh.;12. pii: /j/ijnes.2015.12.issue-1/ijnes2015-0006/ijnes-2015-0006.xml. doi: 10.1515/ijnes-2015-0006. 
[16]. Chiou S.F., Su H.C., Liu K.F., Hwang H.F. [Flipped Classroom: A New Teaching Strategy for Integrating Information Technology Into Nursing Education] Article in Chinese. Hu Li Za Zhi.; 2015, 62(3):5-10. doi: 10.6224/JN.62.3.5.

[17]. Faculty Center for Teaching and Learning, (2017): Bloom's Taxonomy. University of central Florida, available at http://www.fctl.ucf.edu /teachingandlearningresources/coursedesign/bloomstaxonomy/accessed 14/1/2017.

[18]. Liu N., Li X.W., Zhou M.W., and Biering-Sørensen F.The influence of question design on the response to self-assessment in www.elearnSCI. org: a submodule pilot study. Spinal Cord.;2015, 53(8):604-7. doi: 10.1038/sc. 2014.226. Epub 2015 Feb 17.

[19]. Robin, (2015): Blooms Taxonomy, Learning Objectives and Higher Order Thinking. Health Science Center. Available at https://www.unthsc.edu/center-for-innovative-learning/blooms-taxonomy-learning-objectives-and-higher-order-thinking/ accessed at $9 / 1 / 2017$.

[20]. El-Gilany A.H., and Abusaad F.E.S. Self-directed learning readiness and learning styles among Saudi undergraduate nursing students.Nurse Educ Today.; 2013, 33(9):1040-4. doi: 10.1016/j.nedt. 2012.05. 003. Epub 2012 May 27.

[21]. Gagnon M.P., Gagnon J., and Desmartis M. The impact of blended teaching on knowledge, satisfaction, and self-directed learning in nursing undergraduates: a randomized, controlled trial. Nursing Edu Perspectives; 2013, 34: 377-382.

[22]. Said A.B., Ghani N., and Khan A. Examination of Self-Directed Learning Readiness among Baccalaureate Nursing Students in Peshawar Pakistan. Int J Innovative Res 2015, Develop 4.

[23]. Zhang H., and Hsu L.L. The effectiveness of an education program on nurses' knowledge of electrocardiogram interpretation. Int Emerg Nurs.;2013, 21(4):247-51. doi: 10.1016/j.ienj.2012.11.001. Epub 2012 Dec 21.

[24]. Pappas C. (2013): The Adult Learning Theory - Andragogy. Available at https://elearningindustry.com/8-important-characteristicsof-adult-learners.Accessed at 8/1/2017.

Table 1: Pre and post-intervention success rates among Egyptian and Saudi students

\begin{tabular}{|c|c|c|c|c|c|c|}
\hline \multirow{3}{*}{ Satisfactory $(60 \%+)$} & \multicolumn{4}{|c|}{ Time } & \multirow{3}{*}{$\mathrm{X}^{2}$ test } & \multirow{3}{*}{ p-value } \\
\hline & \multicolumn{2}{|c|}{ Pre } & \multicolumn{2}{|c|}{ Post } & & \\
\hline & No. & $\%$ & No. & $\%$ & & \\
\hline \multicolumn{7}{|c|}{ EGYPTIAN $(\mathrm{n}=100)$} \\
\hline \multicolumn{7}{|l|}{ Knowledge level: } \\
\hline Know & 72 & 72.0 & 100 & 100.0 & 32.56 & $<0.001 *$ \\
\hline Compare & 26 & 26.0 & 91 & 91.0 & 87.01 & $<0.001^{*}$ \\
\hline Apply & 76 & 76.0 & 100 & 100.0 & 27.27 & $<0.001^{*}$ \\
\hline Analyze & 45 & 45.0 & 99 & 99.0 & 72.32 & $<0.001^{*}$ \\
\hline Evaluate & 11 & 11.0 & 94 & 94.0 & 138.13 & $<0.001^{*}$ \\
\hline \multicolumn{7}{|l|}{ Question type: } \\
\hline MCQ & 55 & 55.0 & 100 & 100.0 & 58.06 & $<0.001^{*}$ \\
\hline True/False & 84 & 84.0 & 99 & 99.0 & 14.46 & $<0.001^{*}$ \\
\hline List & 33 & 33.0 & 100 & 100.0 & 100.75 & $<0.001^{*}$ \\
\hline Compare/match & 9 & 9.0 & 94 & 94.0 & 144.63 & $<0.001^{*}$ \\
\hline Total & 25 & 25.0 & 99 & 99.0 & 116.21 & $<0.001^{*}$ \\
\hline \multirow{2}{*}{\multicolumn{7}{|c|}{ SAUDI $(n=90)$}} \\
\hline Knowledge level: & & & & & & \\
\hline Know & 39 & 43.3 & 90 & 100.0 & 71.16 & $<0.001^{*}$ \\
\hline Compare & 20 & 22.2 & 85 & 94.4 & 96.57 & $<0.001^{*}$ \\
\hline Apply & 74 & 82.2 & 89 & 98.9 & 14.62 & $<0.001 *$ \\
\hline Analyze & 12 & 13.3 & 90 & 100.0 & 137.65 & $<0.001^{*}$ \\
\hline Evaluate & 6 & 6.7 & 90 & 100.0 & 157.50 & $<0.001^{*}$ \\
\hline \multicolumn{7}{|l|}{ Question type: } \\
\hline MCQ & 34 & 37.8 & 90 & 100.0 & 81.29 & $<0.001^{*}$ \\
\hline True/False & 73 & 81.1 & 89 & 98.9 & 15.80 & $<0.001^{*}$ \\
\hline List & 14 & 15.6 & 90 & 100.0 & 131.54 & $<0.001^{*}$ \\
\hline Compare/match & 0 & 0.0 & 89 & 98.9 & 176.04 & $<0.001^{*}$ \\
\hline Total & 7 & 7.8 & 90 & 100.0 & 154.02 & $<0.001^{*}$ \\
\hline
\end{tabular}

(*) Statistically significant at $p<0.05$

Table 2: Scores of knowledge among Egyptian and Saudi students before and after the intervention

\begin{tabular}{|c|c|c|c|c|c|c|}
\hline & \multicolumn{2}{|c|}{ Egyptian $(n=100)$} & \multicolumn{2}{|c|}{ Saudi $(\mathrm{n}=90)$} & \multirow{2}{*}{$\begin{array}{c}\text { Mann- Whitney } \\
\text { Test }\end{array}$} & \multirow{2}{*}{ p-value } \\
\hline & Mean \pm SD & Median & Mean \pm SD & Median & & \\
\hline \multicolumn{7}{|c|}{ PRE-INTERVENTION } \\
\hline \multicolumn{7}{|l|}{ Knowledge level: } \\
\hline Know & $62.2 \pm 22.4$ & 60.00 & $48.2 \pm 21.8$ & 40.00 & 18.84 & $<0.001^{*}$ \\
\hline Compare & $48.0 \pm 37.6$ & 50.00 & $48.9 \pm 34.3$ & 50.00 & 0.04 & 0.85 \\
\hline Apply & $76.0 \pm 42.9$ & 100.00 & $82.2 \pm 38.4$ & 100.00 & 1.10 & 0.29 \\
\hline Analyze & $54.7 \pm 22.4$ & 50.00 & $38.5 \pm 19.8$ & 33.30 & 23.84 & $<0.001^{*}$ \\
\hline Evaluate & $44.6 \pm 18.1$ & 42.90 & $40.2 \pm 16.4$ & 42.90 & 1.39 & 0.24 \\
\hline \multicolumn{7}{|l|}{ Question type: } \\
\hline MCQ & $60.2 \pm 19.5$ & 60.00 & $50.1 \pm 17.6$ & 50.00 & 10.68 & $0.001^{*}$ \\
\hline True/False & $69.0 \pm 20.2$ & 80.00 & $65.3 \pm 19.8$ & 80.00 & 1.05 & 0.31 \\
\hline List & $41.0 \pm 31.7$ & 33.30 & $22.2 \pm 28.3$ & 0.00 & 18.72 & $<0.001^{*}$ \\
\hline Compare/match & $17.8 \pm 22.9$ & 0.00 & $13.0 \pm 16.3$ & 0.00 & 1.10 & 0.30 \\
\hline Total & $52.6 \pm 14.7$ & 52.40 & $43.3 \pm 13.1$ & 42.90 & 17.74 & $<0.001^{*}$ \\
\hline \multicolumn{7}{|c|}{ POST-INTERVENTION } \\
\hline Knowledge level: & & & & & & \\
\hline
\end{tabular}


Effect of a Self-Instruction Package on Cognitive Performance among Egyptian and Saudi Pediatric ..

\begin{tabular}{|c|c|c|c|c|c|c|}
\hline Know & $96.6 \pm 8.1$ & 100.00 & $98.7 \pm 5.0$ & 100.00 & 4.06 & $0.04 *$ \\
\hline Compare & $95.5 \pm 14.4$ & 100.00 & $97.2 \pm 11.5$ & 100.00 & 0.82 & 0.37 \\
\hline Analyze & $94.0 \pm 11.4$ & 100.00 & $97.0 \pm 6.9$ & 100.00 & 3.41 & 0.06 \\
\hline \multicolumn{7}{|l|}{ Question type: } \\
\hline MCQ & $96.3 \pm 9.0$ & 100.00 & $98.1 \pm 4.5$ & 100.00 & 0.44 & 0.51 \\
\hline True/False & $96.6 \pm 9.9$ & 100.00 & $96.2 \pm 9.4$ & 100.00 & 0.42 & 0.52 \\
\hline Compare/match & $87.0 \pm 21.1$ & 100.00 & $94.8 \pm 13.1$ & 100.00 & 8.44 & $0.004^{*}$ \\
\hline Total & $94.6 \pm 8.6$ & 100.00 & $96.8 \pm 4.7$ & 100.00 & 1.64 & 0.20 \\
\hline
\end{tabular}

(*) Statistically significant at $p<0.05$

Table 3: Correlation matrix of students' knowledge scores by level of knowledge

\begin{tabular}{|c|c|c|c|c|c|}
\hline \multirow[t]{2}{*}{ Level of knowledge (ILOS) } & \multicolumn{5}{|c|}{ Spearman's rank correlation coefficient } \\
\hline & Know & Compare & Apply & Analyze & Evaluate \\
\hline Compare & $.543 * *$ & & & & \\
\hline Analyze & $.751 * *$ & $.640 * *$ & $.319 * *$ & & \\
\hline Evaluate & $.775 * *$ & $.664 * *$ & $.361 * *$ & $.828 * *$ & \\
\hline
\end{tabular}

(**) Statistically significant at $p<0.01$

Table 4: Best fitting multiple linear regression model for students' knowledge scores by level of learning outcome

\begin{tabular}{|c|c|c|c|c|c|c|c|}
\hline & \multicolumn{2}{|c|}{$\begin{array}{l}\text { Unstandardized } \\
\text { Coefficients }\end{array}$} & \multirow[t]{2}{*}{$\begin{array}{l}\text { Standardized } \\
\text { Coefficients }\end{array}$} & \multirow[t]{2}{*}{ t-test } & \multirow[t]{2}{*}{$\mathrm{p}$-value } & \multicolumn{2}{|c|}{$\begin{array}{l}95 \% \text { Confidence } \\
\text { Interval for B }\end{array}$} \\
\hline & $\mathrm{B}$ & Std. Error & & & & Lower & Upper \\
\hline \multicolumn{8}{|c|}{ Know } \\
\hline Constant & 4.49 & 3.79 & & 1.183 & 0.238 & -2.97 & 11.95 \\
\hline Egypt nationality & 5.96 & 1.73 & 0.11 & 3.447 & 0.001 & 2.56 & 9.35 \\
\hline Module & 42.00 & 1.73 & 0.78 & 24.343 & $<0.001$ & 38.61 & 45.39 \\
\hline \multicolumn{8}{|c|}{ Model ANOVA: $\mathrm{F}=302.24, \mathrm{p}<0.001$} \\
\hline \multicolumn{8}{|c|}{ Compare } \\
\hline Constant & 053 & 439 & & م 12 & 0005 & 811 & 016 \\
\hline Module & 47.89 & 2.78 & 0.66 & 17.246 & $<0.001$ & 42.43 & 53.36 \\
\hline \multicolumn{8}{|c|}{ Model ANOVA: $\mathrm{F}=297.44, \mathrm{p}<0.001$} \\
\hline \multicolumn{8}{|c|}{ Apply } \\
\hline & & & & & & & \\
\hline Constant & 44.68 & 7.66 & & 5.832 & $<0.001$ & 29.62 & 59.74 \\
\hline Female gender & 7.86 & 3.45 & .11 & 2.282 & .023 & 1.09 & 14.64 \\
\hline Module & 20.53 & 2.99 & .33 & 6.853 & $<0.001$ & 14.64 & 26.42 \\
\hline \multicolumn{8}{|c|}{$\begin{array}{l}\text { Model ANOVA: } F=26.09, p<0.001 \\
\text { nationality }\end{array}$} \\
\hline \multicolumn{8}{|c|}{ Analyze } \\
\hline Constant & -11.41 & 3.86 & & 2.957 & 0.003 & -19.00 & -3.82 \\
\hline Egypt nationality & 6.56 & 1.76 & 0.11 & 3.731 & $<0.001$ & 3.10 & 10.01 \\
\hline Module & 48.42 & 1.75 & 0.81 & 27.594 & $<0.001$ & 44.97 & 51.87 \\
\hline \multicolumn{8}{|c|}{ Model ANOVA: $\mathrm{F}=387.66, \mathrm{p}<0.001$} \\
\hline \multicolumn{8}{|c|}{ Evaluate } \\
\hline Constant & -9.62 & 2.34 & & 4.112 & $<0.001$ & -14.23 & -5.02 \\
\hline Module & 52.11 & 1.48 & 0.88 & 35.199 & $<0.001$ & 49.19 & 55.02 \\
\hline
\end{tabular}

Table 5: Best fitting multiple linear regression model for students' knowledge scores by types of questions

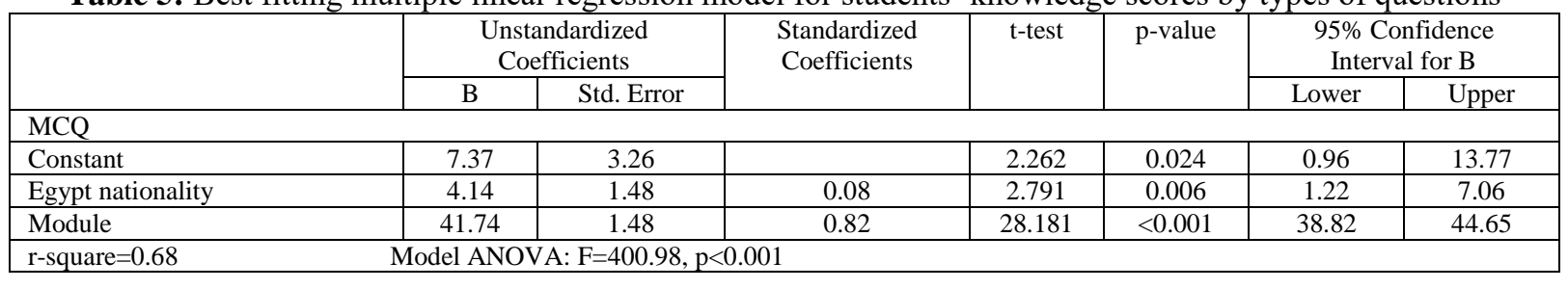


Effect of a Self-Instruction Package on Cognitive Performance among Egyptian and Saudi Pediatric ..

\begin{tabular}{|c|c|c|c|c|c|c|c|}
\hline \multicolumn{8}{|c|}{ Variables entered and excluded: none } \\
\hline \multicolumn{8}{|c|}{ True/False } \\
\hline Constant & 38.11 & 2.55 & & 14.932 & $<0.001$ & 33.09 & 43.12 \\
\hline Module & 29.16 & 1.61 & 0.68 & 18.066 & $<0.001$ & 25.98 & 32.33 \\
\hline \multicolumn{8}{|c|}{$\begin{array}{l}\text { Model ANOVA: } \mathrm{F}=326.37, \mathrm{p}<0.001 \\
\text { nationality }\end{array}$} \\
\hline \multicolumn{8}{|l|}{ List } \\
\hline Constant & -43.78 & 5.23 & & 8.368 & $<0.001$ & -54.07 & -33.49 \\
\hline Egypt nationality & 7.65 & 2.38 & 0.10 & 3.210 & 0.001 & 2.96 & 12.33 \\
\hline Module & 64.21 & 2.38 & 0.81 & 26.990 & $<0.001$ & 59.53 & 68.89 \\
\hline \multicolumn{8}{|c|}{ Model ANOVA: $F=369.39, p<0.001$} \\
\hline \multicolumn{8}{|c|}{ Compare/differentiate/match } \\
\hline Constant & -59.82 & 3.12 & & 19.204 & $<0.001$ & -65.95 & -53.70 \\
\hline Module & 75.26 & 1.97 & 0.89 & 38.200 & $<0.001$ & 71.39 & 79.14 \\
\hline
\end{tabular}

